\title{
Epitaxy of Tin Dioxide on Titanium Dioxide by Mist Chemical Vapor Deposition
}

\author{
Thant Zin Win ${ }^{1}$, Katsuhiko Inaba ${ }^{2}$, Shintaro Kobayashi ${ }^{3}$, \\ Yuki Kanetake ${ }^{1}$, and Yusui Nakamura ${ }^{1,4^{*}}$ \\ 1 GSST, Kumamoto University, 2-39-1, Kurokami, Chuo-ku, Kumamoto 860-8555, Japan \\ 2 X-ray Res. Lab., Rigaku Corporation, 3-9-12, Matsubara, Akishima 196-8666, Japan \\ 3 Appl. Lab., Rigaku Corporation, 3-9-12, Matsubara, Akishima 196-8666, Japan \\ 4 FAST, Kumamoto University, 2-39-1, Kurokami, Chuo-ku, Kumamoto 860-8555, Japan \\ * Corresponding author: Fax: 81-96-342-3842, and e-mail: yusui@cs.kumamoto-u.ac.jp
}

Tin dioxide $\left(\mathrm{SnO}_{2}\right)$ films were epitaxially grown on $m$-plane sapphire and (001) plane titanium dioxide $\left(\mathrm{TiO}_{2}\right)$ substrates using mist chemical vapor deposition. The quality of $\mathrm{SnO}_{2}$ film was evaluated by full width at half maximum (FWHM) of X-ray diffraction (XRD) $\omega$-rocking curve. The lowest value of FWHM was $0.06^{\circ}$ for the $\mathrm{SnO}_{2}$ film on $\mathrm{TiO}_{2}$ substrate, which was lower than the other reported values. Not only vertical lattice constant but also lateral one were measured by XRD reciprocal space mapping (RSM) and transmission electron microscopy (TEM). Then, the lattice constants of the $\mathrm{SnO}_{2}$ film on $\mathrm{TiO}_{2}$ substrate were the same as those of the bulk $\mathrm{SnO}_{2}$. From the results of TEM and electron backscattering diffraction (EBSD) observations, the quality of the $\mathrm{SnO}_{2}$ film was higher at upper portion of the $\mathrm{SnO}_{2}$ film. These results indicated that high-quality single crystal $\mathrm{SnO}_{2}$ film was formed on $\mathrm{TiO}_{2}$ substrate.

Key words: hetero-epitaxy, X-ray diffraction, rocking curve, tin oxide, mist-CVD

\section{INTRODUCTION}

Tin dioxide $\left(\mathrm{SnO}_{2}\right)$ is a multipurpose semiconductor with high transparency, physical and chemical stabilities, and excellent electrical properties. Recently $\mathrm{SnO}_{2}$ is used for gas sensors and transparent conducting films [1-7]. On the other hand, $\mathrm{SnO}_{2}$ with rutile structure has been attracted much attention for several applications such as power devices, optical devices, and thin-film transistors due to its wide bandgap $(3.60 \sim 3.99 \mathrm{eV})$, high exciton binding energy $(0.13 \mathrm{eV})$, and high electron mobility (250 $\left.\mathrm{cm}^{2} \mathrm{~V}^{-1} \mathrm{~s}^{-1}\right)$ [8-15]. In order to apply to commercial devices with high reliability, it is necessary to form the high-quality $\mathrm{SnO}_{2}$ single crystal. For example, Schottky barrier diode can be formed with a structure of high-quality non-doped $\mathrm{SnO}_{2}$ film on n-type $\mathrm{TiO}_{2}$ substrates.

Currently, there are many reports on $\mathrm{SnO}_{2}$ film deposition using various techniques such as molecular beam epitaxy (MBE), metal-oxide chemical vapor deposition (MOCVD), sputtering, vacuum evaporation, atomic layer deposition (ALD), and others [16-28]. However, there are only several articles on formation of $\mathrm{SnO}_{2}$ single crystal with high quality. With the help of vacuum techniques such as MBE, MOCVD, and ALD, $\mathrm{SnO}_{2}$ single crystals were formed on $m$-plane and $r$-plane sapphire substrates. However, the crystal quality was not very high, where full widths at half maximum (FWHMs) of X-ray diffraction (XRD) $\omega$-rocking curve of $\mathrm{SnO}_{2}$ films were $0.20^{\circ}$ to $1.60^{\circ}[9,19,21,26]$. Furthermore, $\mathrm{SnO}_{2}$ single crystals on titanium dioxide $\left(\mathrm{TiO}_{2}\right)$ substrates were reported also using vacuum techniques, but the FWHM values were $0.48^{\circ}$ to $0.61^{\circ}$, and thus, the improvement is still necessary $[16,29,30]$. On the other hand, $\mathrm{SnO}_{2}$ can be grown using an inexpensive technique such as mist chemical vapor deposition (mist-CVD), which can be operated at atmospheric pressure without vacuum systems $[31,32]$. Additionally, mist-CVD system is easy to operate safely, and is environmental friendly technique. Furthermore, high-quality single crystal oxide films such as $\mathrm{ZnO}, \mathrm{Ga}_{2} \mathrm{O}_{3}$, and $\mathrm{ZnS} / \mathrm{ZnO}$ heterostructure have been grown using mist-CVD [33-35].

Although various techniques including mist-CVD are available for $\mathrm{SnO}_{2}$ film, there are some difficulties to grow the high-quality epitaxial $\mathrm{SnO}_{2}$ thin film, due to the lattice mismatch between $\mathrm{SnO}_{2}$ thin film and the substrates. Recently, the growth of $\mathrm{SnO}_{2}$ single crystal films on various substrates such as $r$-plane, $a$-plane, and $m$-plane sapphire have been reported [36-39].

In this paper, we report high-quality $\mathrm{SnO}_{2}$ single crystal films formed on $m$-plane sapphire and (001) plane $\mathrm{TiO}_{2}$ substrates by mist-CVD. The quality of $\mathrm{SnO}_{2}$ film was evaluated by FWHM of XRD $\omega$-rocking curve.

\section{EXPERIMENTAL PROCEDURES}

The $\mathrm{SnO}_{2}$ films were grown on both low-cost sapphire substrate and relatively high-cost $\mathrm{TiO}_{2}$ substrate using mist-CVD with tin acetate $\left(\mathrm{Sn}\left(\mathrm{CH}_{3} \mathrm{COO}\right)_{4}\right)$ aqueous solution of $0.04 \mathrm{~mol} / \mathrm{L}$. In case of this solution, it was possible to grow high-quality $\mathrm{SnO}_{2}$ films in our previous study $[40,41]$. The surface orientation of the sapphire substrate $(50 \mathrm{~mm}$-diameter circular shape) was $m$-plane because the lattice mismatch of the $\mathrm{SnO}_{2}$ (001) planes and the $m$-plane sapphire is less compared to other sapphire planes. In this growth, three small square lattices of $\mathrm{SnO}_{2}$ (001) plane are expected to be formed on one large rectangle lattice of $m$-plane sapphire, namely domain matching epitaxy $[36,42,43]$. In case of $\mathrm{TiO}_{2}$ substrate (10 $\mathrm{mm}$ square shape), the surface orientation was (001) plane and the crystal structure was rutile, which are the same as the $\mathrm{SnO}_{2}$ films. The $\mathrm{TiO}_{2}$ substrate was cleaned 
with an ultrasonic cleaner using the solutions of acetone, ethanol, and deionized water for three times with the duration of two minutes. After the cleaning, $\mathrm{SnO}_{2}$ films were grown by mist-CVD. The detailed growth conditions were described in Table I.

Table I. Growth conditions of $\mathrm{SnO}_{2}$ films by mist-CVD

\begin{tabular}{|l|c|c|}
\hline $\begin{array}{l}\text { Source } \\
\text { solution }\end{array}$ & \multicolumn{2}{|c|}{$\begin{array}{l}\text { Tin acetate }\left(\mathrm{Sn}\left(\mathrm{CH}_{3} \mathrm{COO}\right)_{4}\right) \\
\text { aqueous solution }(0.04 \mathrm{~mol} / \mathrm{L})\end{array}$} \\
\hline Substrate & Sapphire & Titanium dioxide $\left(\mathrm{TiO}_{2}\right)$ \\
\hline Temperature & \multicolumn{2}{|c|}{$650^{\circ} \mathrm{C}$} \\
\hline Flow rate & \multicolumn{2}{|c|}{$3 \mathrm{~L} /$ minute $\left(\right.$ Carrier gas: $\left.\mathrm{N}_{2}\right)$} \\
\hline Growth rate & $1.1 \mu \mathrm{m} / \mathrm{h}$ & $1.0 \mu \mathrm{m} / \mathrm{h}$ \\
\hline
\end{tabular}

After the growth, the surface morphology of these $\mathrm{SnO}_{2}$ films was observed by field emission scanning electron microscopy (FE-SEM, JSM-7600F, JEOL). The thickness of $\mathrm{SnO}_{2}$ films was measured by cross-sectional SEM observation because it was unable to etch the $\mathrm{SnO}_{2}$ film. Then, the crystal quality of $\mathrm{SnO}_{2}$ films was analyzed by high-resolution XRD $\left(9 \mathrm{~kW}, \mathrm{CuK} \alpha_{1}, \lambda=0.154059 \mathrm{~nm}\right.$, Smartlab, Rigaku), where Ge 220 two-bounce monochromator-collimator device was used as the incident optics system. Degree of relaxation of $\mathrm{SnO}_{2}$ lattice due to epitaxial constraint on $\mathrm{TiO}_{2}$ substrate was characterized by the reciprocal space mapping (RSM) of XRD. Then, the cross-section of the sample was observed by high-resolution transmission electron microscopy (HR-TEM, $200 \mathrm{kV}$, JEM-2100plus, JEOL) and electron backscatter diffraction (EBSD, NB5000, Hitachi). The micron-size samples (100 nm-thick, $10 \mu \mathrm{m}$-width, 10 $\mu \mathrm{m}$-height) were formed for cross-sectional TEM analysis by etching the $\mathrm{SnO}_{2}$ films with focus ion beam (FIB, NB5000, Hitachi).

\section{RESULTS AND DISCUSSION}

The SEM images of $\mathrm{SnO}_{2}$ films on $m$-plane sapphire and $(001) \mathrm{TiO}_{2}$ substrates are shown in Fig. 1. The surface morphologies of the $\mathrm{SnO}_{2}$ films have many bright lines and dark spots. Thus, we measured the surface roughnesses by atomic force microscopy. The roughnesses of the $\mathrm{SnO}_{2}$ surfaces on sapphire and $\mathrm{TiO}_{2}$ substrates were $7.4 \mathrm{~nm}$ and $7.9 \mathrm{~nm}$ in root mean square (RMS), respectively. These values were smaller than the case of $\mathrm{SnO}_{2}$ film (RMS: $29 \mathrm{~nm}$ ) formed on sapphire using tin chloride solution in our previous study [40].
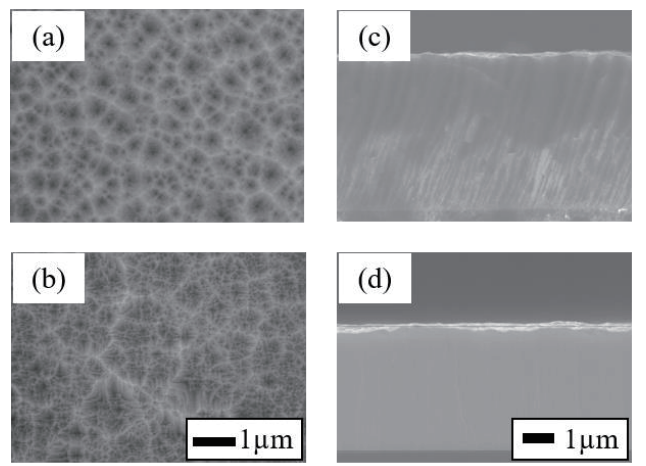

Fig. 1. Surface SEM images; (a) $5 \mu \mathrm{m}$-thick $\mathrm{SnO}_{2}$ film on $m$-plane sapphire, (b) $4 \mu$ m-thick $\mathrm{SnO}_{2}$ film on $\mathrm{TiO}_{2}$. Cross-sectional SEM images; (c) and (d) corresponding to (a) and (b), respectively.
From the cross-sectional SEM observation, thicknesses of the $\mathrm{SnO}_{2}$ films were $5 \mu \mathrm{m}$ on the sapphire substrate, and $4 \mu \mathrm{m}$ on the $\mathrm{TiO}_{2}$ substrate, respectively. The reason of forming thick $\mathrm{SnO}_{2}(4 \mu \mathrm{m})$ on the $\mathrm{TiO}_{2}$ substrate was to investigate thickness dependence of the crystal quality. Thus, we measured the crystal quality with Kernel average misorientation (KAM) values for each vertical position from the interface of $\mathrm{SnO}_{2}$ and $\mathrm{TiO}_{2}$ as mentioned later.

The thickness distribution of the $\mathrm{SnO}_{2}$ film on $\mathrm{TiO}_{2}$ is shown in Fig. 2. The thickness was about $4 \mu \mathrm{m}$ and almost uniform over $5 \mathrm{~mm}$ on the sample.

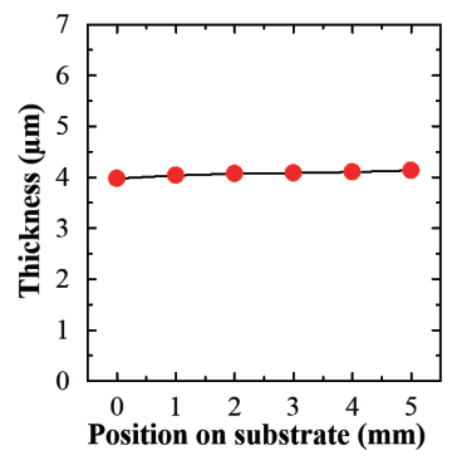

Fig. 2. Thickness distribution of $\mathrm{SnO}_{2}$ film on $\mathrm{TiO}_{2}$ substrate

To characterize the $\mathrm{SnO}_{2}$ films, XRD $\theta-2 \theta$ scan was performed as shown in Fig. 3. The 002 reflection peaks of $\mathrm{SnO}_{2}$ films formed on sapphire and $\mathrm{TiO}_{2}$ substrates were clearly observed. In addition, 30-30 reflection peak of sapphire substrate and 002 reflection peak of $\mathrm{TiO}_{2}$ substrate were also observed. From this result, $\mathrm{SnO}_{2}$ films were grown with [001] orientation both on sapphire and $\mathrm{TiO}_{2}$ substrates.

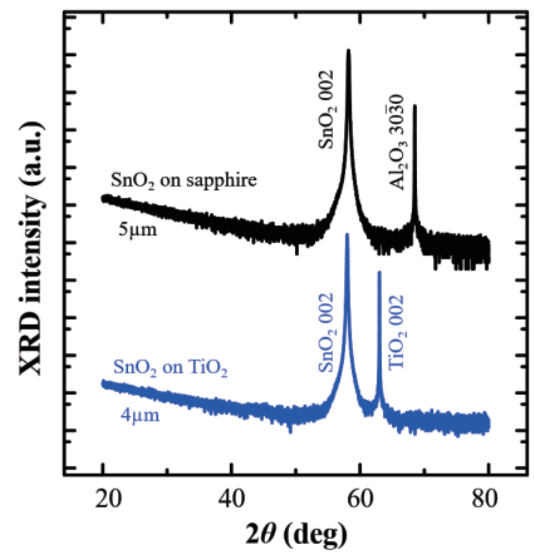

Fig. 3. XRD $\theta-2 \theta$ patterns of $\mathrm{SnO}_{2}$ film on sapphire and $\mathrm{TiO}_{2}$ substrates

To quantitatively evaluate crystal quality of the $\mathrm{SnO}_{2}$ films, XRD $\omega$-rocking curves were measured as shown in Fig. 4, where the FWHMs of $\mathrm{SnO}_{2}$ films on sapphire and $\mathrm{TiO}_{2}$ substrates were as narrow as $0.09^{\circ}$ and $0.06^{\circ}$, respectively. These results demonstrated that our growth method and the conditions were much better than other growth methods with the vacuum systems. Especially in cases of the $\mathrm{SnO}_{2}$ films on $\mathrm{TiO}_{2}$ substrate, the FWHMs were narrower and also the intensities were higher than 
those on sapphire substrate. It showed that the $\mathrm{SnO}_{2}$ film grown on $\mathrm{TiO}_{2}$ had higher quality. This is because $\mathrm{SnO}_{2}$ and $\mathrm{TiO}_{2}$ have the same crystal structure of rutile, and the lattice mismatches between $\mathrm{SnO}_{2}$ and $\mathrm{TiO}_{2}(+3.1 \%$ in both [100] and [010] orientations) are smaller than those between $\mathrm{SnO}_{2}$ and $m$-plane sapphire $(+9.46 \%$ in [0001] orientation and $-0.42 \%$ in [11-20] orientation).

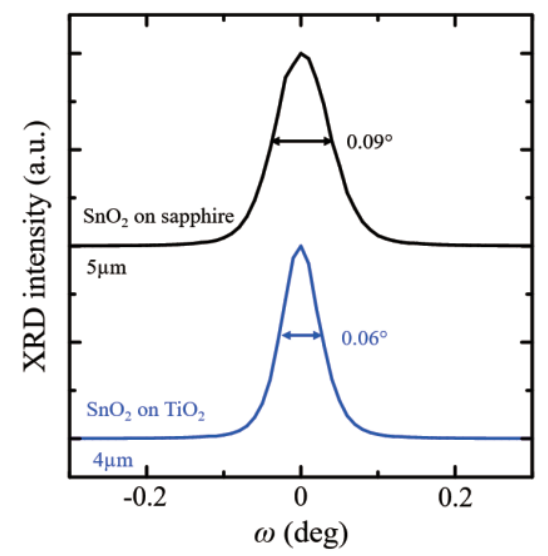

Fig. 4. XRD $\omega$-rocking curves of $\mathrm{SnO}_{2}$ film on sapphire and $\mathrm{TiO}_{2}$ substrates

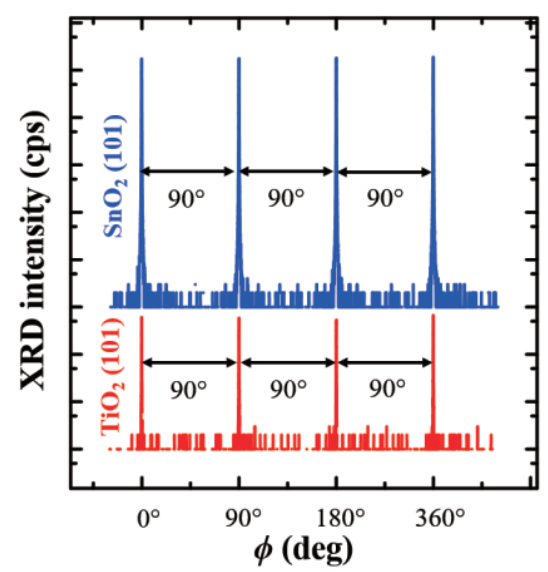

Fig. 5. XRD $\phi$-scan of $\mathrm{SnO}_{2}$ film on $\mathrm{TiO}_{2}$ substrate

To identify lateral crystal alignment of the $\mathrm{SnO}_{2}$ film grown on $\mathrm{TiO}_{2}$ substrate, XRD $\phi$-scan was performed as shown in Fig. 5. The (101) planes were used as monitoring planes for both $\mathrm{SnO}_{2}$ film and $\mathrm{TiO}_{2}$ substrate, where $\chi$-axis of the sample was tilted at $33.9^{\circ}$ and $32.8^{\circ}$ for $\mathrm{SnO}_{2}$ film and $\mathrm{TiO}_{2}$ substrate, respectively. Four peaks evenly spaced with $90^{\circ}$ were observed for (101) planes for both $\mathrm{SnO}_{2}$ film and $\mathrm{TiO}_{2}$ substrate, and peak positions of $\mathrm{SnO}_{2}$ film corresponded to those of $\mathrm{TiO}_{2}$ substrate. Therefore, $\mathrm{SnO}_{2}$ film and $\mathrm{TiO}_{2}$ substrate have four-fold symmetry in the [001] orientation. From the results of XRD $\theta-2 \theta$ and $\phi$ scans, it was indicated that the $\mathrm{SnO}_{2}$ film was single crystal, and the epitaxial orientation relationship was (001) [100] $\mathrm{SnO}_{2} \|(001)[100] \mathrm{TiO}_{2}$.

The crystal alignment and epitaxial relationship was also verified by XRD reciprocal space map (RSM) measurement with scintillation counter (SC) as shown in Fig. 6. Before the measurement, we adjusted the (001) plane of the $\mathrm{TiO}_{2}$ substrate. From the RSM, the lattice constants were calculated by the following equation:

$$
q=1 / d=2 \sin \left(\theta_{\mathrm{B}}\right) / \lambda
$$

where $q$ is a distance from the origin in reciprocal space coordinates, $d$ is an interplanar distance, $\lambda$ is the wavelength of X-ray, and $\theta_{\mathrm{B}}$ is Bragg angle. The XRD peak of the $\mathrm{SnO}_{2}$ film was stronger than the $\mathrm{TiO}_{2}$ substrate peak because of thick $\mathrm{SnO}_{2}$ film with thickness of $4 \mu \mathrm{m}$. Symmetric 002 reflections for both $\mathrm{SnO}_{2}$ film and $\mathrm{TiO}_{2}$ substrate were observed at the alignment of reciprocal coordinate $q_{\mathrm{x}}=0$. Hence, (001) plane of $\mathrm{SnO}_{2}$ film should be parallel to (001) plane of $\mathrm{TiO}_{2}$ substrate.

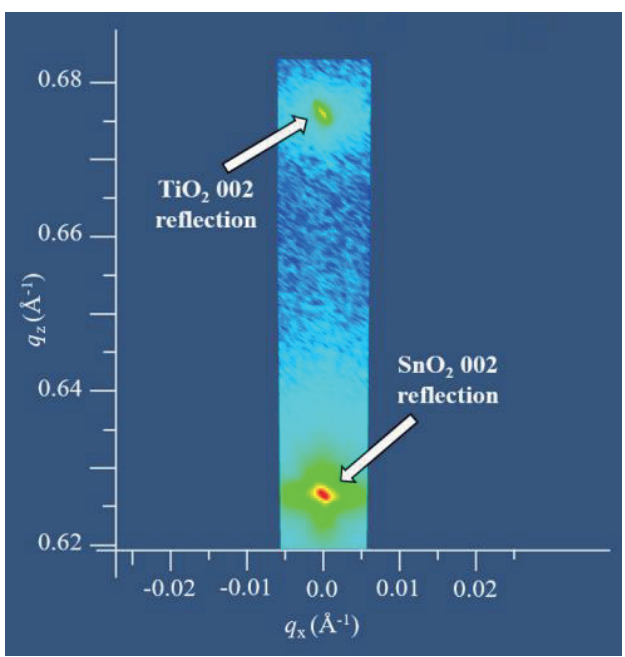

Fig. 6. Symmetric RSM data of $\mathrm{SnO}_{2}$ film on $\mathrm{TiO}_{2}$ substrate

Generally, a hetero-epitaxial film has strain because of the lattice mismatch between the film and the substrate. Then, not only vertical lattice constant but also lateral one of the $\mathrm{SnO}_{2}$ film were measured by the XRD RSM measurement for 202 reflections of both the epitaxial $\mathrm{SnO}_{2}$ film and the $\mathrm{TiO}_{2}$ substrate. The result of asymmetric data of XRD RSM was shown in Fig. 7. From the 202 reflection peak, the lateral and vertical lattice constants of $\mathrm{SnO}_{2}$ film were obtained to be $a=4.73 \AA$ (lateral) and $c=$ $3.19 \AA$ (vertical), respectively. Therefore, the lattice constants of the $\mathrm{SnO}_{2}$ film were the same as those of $\mathrm{SnO}_{2}$ bulk crystal, which indicated that the strain of the $\mathrm{SnO}_{2}$ film was relaxed.

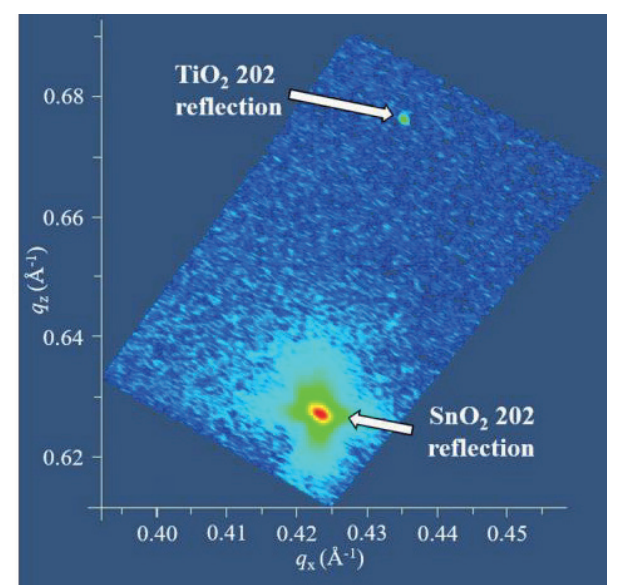

Fig. 7. Asymmetric RSM data of $\mathrm{SnO}_{2}$ film on $\mathrm{TiO}_{2}$ substrate 
To observe crystal defects in the $\mathrm{SnO}_{2}$ film, HR-TEM was used. The bright field image of the cross-sectional $\mathrm{SnO}_{2}$ film with (110) plane was shown in Fig. 8. Though there were many defects at the interface of $\mathrm{SnO}_{2}$ film and $\mathrm{TiO}_{2}$ substrate, the defects were decreased with the thickness of $\mathrm{SnO}_{2}$ film.

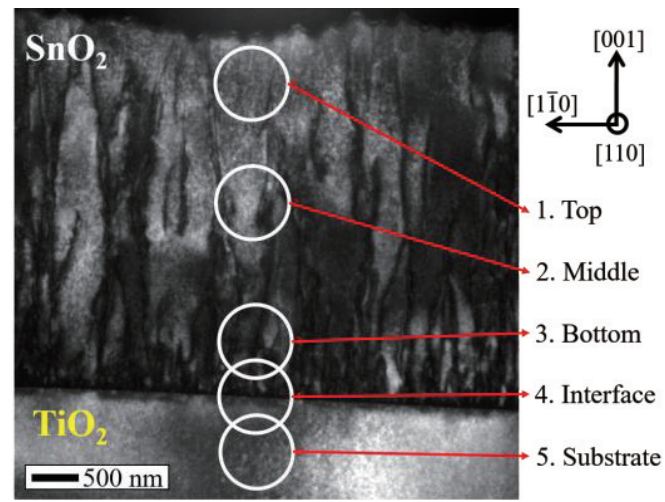

Fig. 8. Bright field TEM image of $\mathrm{SnO}_{2}$ film on $\mathrm{TiO}_{2}$ substrate, where five positions for SAED observation were shown.

The selected area electron diffraction (SAED) patterns at the top area of the $\mathrm{SnO}_{2}$ film were measured as shown in Fig. 9 using the cross-sectional TEM sample. The lattice constants of $\mathrm{SnO}_{2}$ film calculated from the SAED patterns at top, middle, and bottom areas in Fig. 8 are 4.72 $\AA$ for $a$-axis and $3.18 \AA$ for $c$-axis, which are almost the same as those of $\mathrm{SnO}_{2}$ bulk crystal.

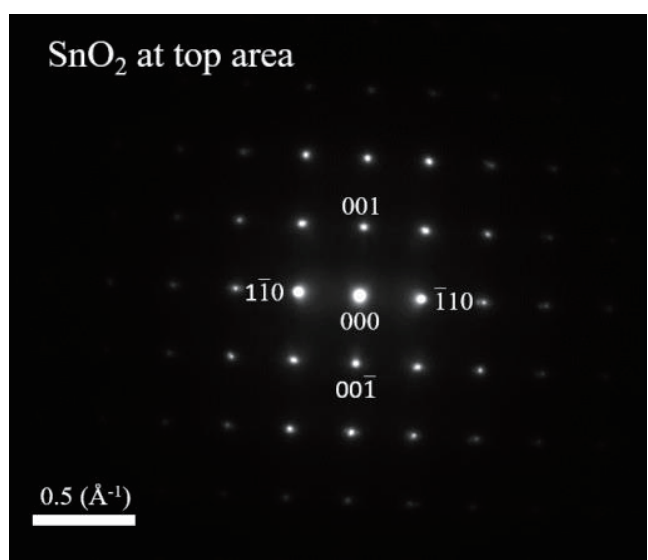

Fig. 9. SAED pattern at top area of $\mathrm{SnO}_{2}$ film on $\mathrm{TiO}_{2}$ substrate

The SAED pattern was measured also at the interface of $\mathrm{SnO}_{2}$ film and $\mathrm{TiO}_{2}$ substrate as shown in Fig. 10 (a), and Fig. 10 (b) is the corresponding schematic diagram. From these results including XRD and SEAD, the $\mathrm{SnO}_{2}$ film was shown to be a single crystal with a rutile structure, and the epitaxial orientation relationship was (001) [100] $\mathrm{SnO}_{2} \|(001)$ [100] $\mathrm{TiO}_{2}$.

In Fig. 10 (a), reciprocal lattice lengths of $\mathrm{TiO}_{2}$ were larger than those of $\mathrm{SnO}_{2}$, since lattice constants of $\mathrm{TiO}_{2}$ were smaller than those of $\mathrm{SnO}_{2}$. From the SEAD pattern in Fig. 10 (a), lattice constants were $4.72 \AA$ for $a$-axis and $3.18 \AA$ for $c$-axis of $\mathrm{SnO}_{2}$ film, which were also almost the same as the values of $\mathrm{SnO}_{2}$ bulk crystal. These results clearly showed that strain of $\mathrm{SnO}_{2}$ film was relaxed not only at the top area of $\mathrm{SnO}_{2}$ film but also near the interface. Though the critical thickness of $\mathrm{SnO}_{2}$ film on $\mathrm{TiO}_{2}$ substrate was not found in literature, it is likely to be several $\mathrm{nm}$ as other materials. For example, in case of indium gallium arsenide film on indium phosphide substrate $(\mathrm{InGaAs} / \mathrm{InP})$ with a lattice mismatch of $+3 \%$, the critical thickness was about $5 \mathrm{~nm}$ [44]. As described above, the lattice mismatches between $\mathrm{SnO}_{2}$ and $\mathrm{TiO}_{2}$ was also $+3.1 \%$. Thus, the transition region of the lattice constant of $\mathrm{SnO}_{2}$ film is probably very thin (several $\mathrm{nm}$ ), compared to the SAED observation area of $800 \mathrm{~nm}(400$ $\mathrm{nm}$ for $\mathrm{SnO}_{2}$ area) as indicated with the circle in Fig. 8. Therefore, different $\mathrm{SnO}_{2}$ lattice constant in the transition region did not seem to be detected.

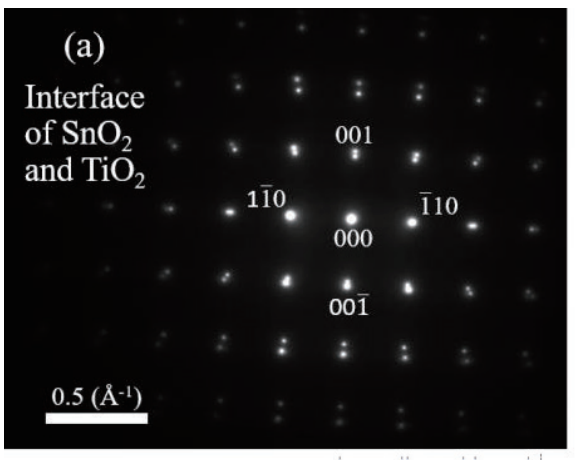

(b)

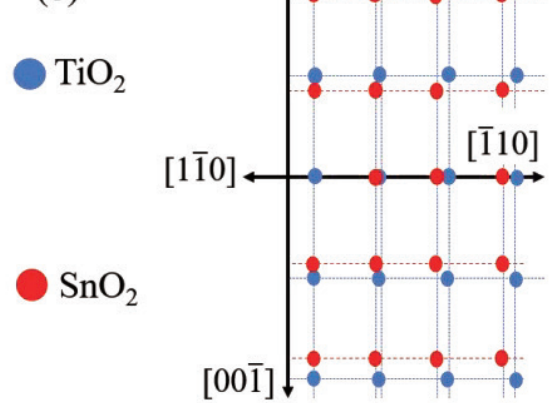

Fig. 10. (a) SAED pattern at the interface area of $\mathrm{SnO}_{2}$ film on $\mathrm{TiO}_{2}$ substrate, (b) Schematic diagram of the SAED pattern of (a)

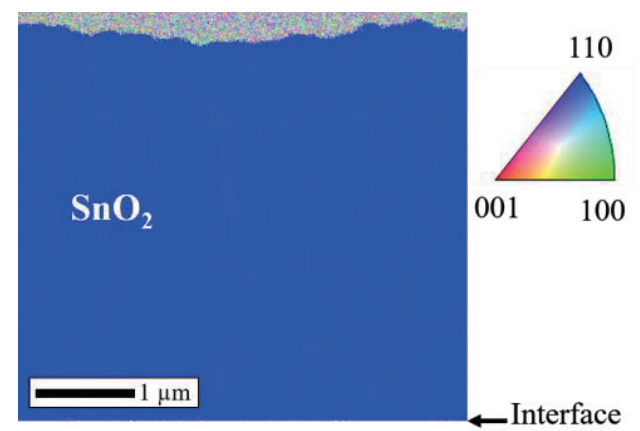

Fig. 11. Inverse pole figure of $\mathrm{SnO}_{2}$ film on $\mathrm{TiO}_{2}$ substrate

The cross-sectional TEM sample was also used for EBSD measurement. The scan step of EBSD was $10 \mathrm{~nm}$ using a scan mode of hexagonal grid. Figure 11 shows the cross-sectional mapping of inverse pole figure (IPF) for $\mathrm{SnO}_{2}$ film, in which only (110) plane was observed. Also 
from EBSD data, we analyzed the local misorientation of $\mathrm{SnO}_{2}$ crystal with KAM using the orientation imaging microscopy (OIM) software as shown in Fig. 12. Usually, the KAM analysis is used to evaluate misorientation angle of each grain in poly-crystal samples, but we used it for our single crystal film. In Fig. 12, blue and green colors correspond to small and large misorientation angles, respectively. Then, the portions with green color corresponded to defect areas in TEM image of Fig. 8.

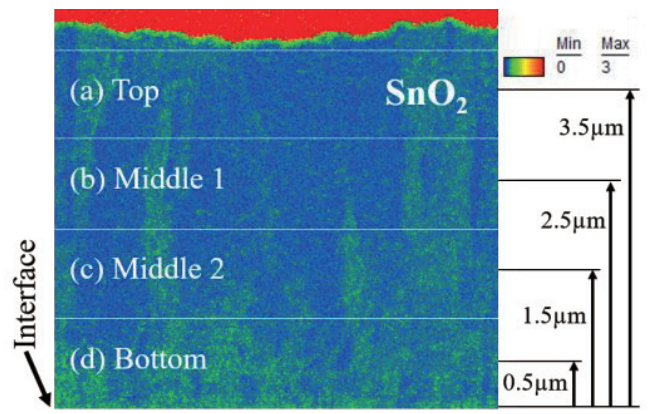

Fig. 12. Kernel average misorientation map of $\mathrm{SnO}_{2}$ film on $\mathrm{TiO}_{2}$ substrate with showing vertical positions from the interface.

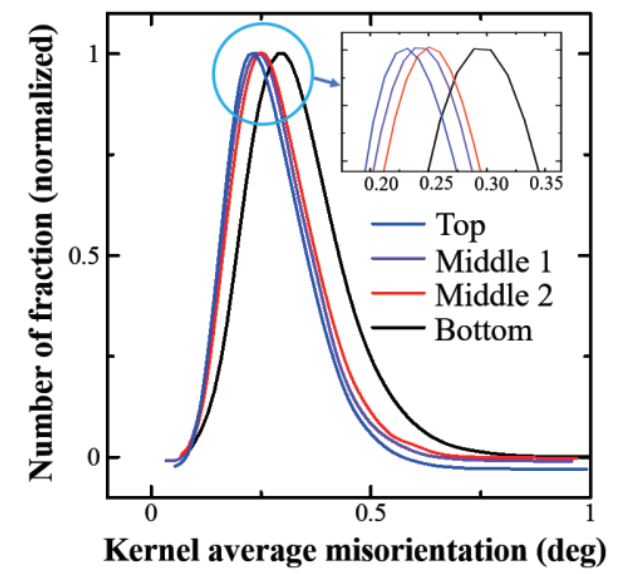

Fig. 13. Kernel average misorientation charts for the four positions of $\mathrm{SnO}_{2}$ film (See Fig. 12).

Using the data of Fig. 12, the misorientation angles were separately obtained for four portions (top, middle 1 , middle 2, and bottom) in the cross-section of the $\mathrm{SnO}_{2}$ film. The KAM charts for the four portions were shown in Fig. 13, where the peak amplitudes of KAM were normalized. Then, the peak angles of KAM were plotted in Fig. 14. The KAM peak angle at the bottom area was $0.30^{\circ}$ while the value at the top area was reduced to $0.23^{\circ}$. According to this result, it was shown that the misorientation angles monotonically decreased with the thickness of the $\mathrm{SnO}_{2}$ film. Therefore, the $\mathrm{SnO}_{2}$ film grown on $\mathrm{TiO}_{2}$ substrate was shown to have higher quality at the top area compared to bottom area. However, in this KAM analysis, the angle value can be used only for qualitative discussion and not for quantitative one [45]. Additionally, in case of FWHM in XRD rocking curve, tilt angle of mosaic structure is detected. On the contrary, in case of KAM, not only tilt angle (vertical misorientation), but also twist angle (lateral misorientation) are detected. Thus, the angles of KAM $\left(0.23-0.30^{\circ}\right)$ should be larger than FWHM $\left(0.06^{\circ}\right)$ of rocking curve, and quantitative comparison is not possible.

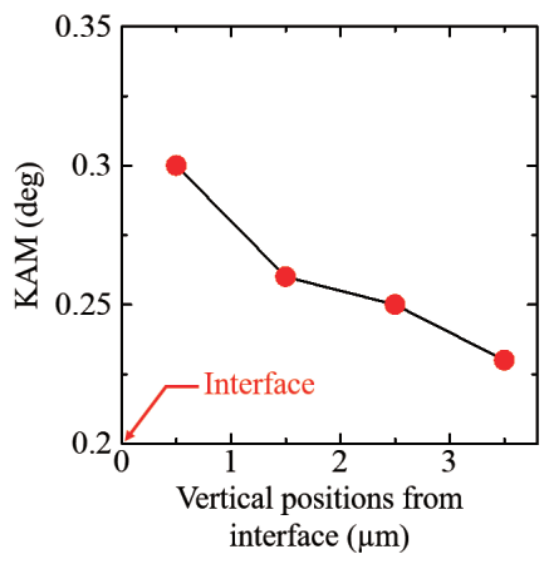

Fig. 14. Peaks of Kernel average misorientation for vertical positions from the interface of $\mathrm{SnO}_{2}$ and $\mathrm{TiO}_{2}$.

\section{CONCLUSION}

The high-quality $\mathrm{SnO}_{2}$ films were grown on sapphire and $\mathrm{TiO}_{2}$ substrates by mist-CVD using $\mathrm{Sn}\left(\mathrm{CH}_{3} \mathrm{COO}\right)_{4}$ aqueous solution. The narrow FWHM of XRD $\omega$-rocking curve was obtained to be $0.06^{\circ}$ on $\mathrm{TiO}_{2}$ substrate, which is narrower than other reported values. The $\mathrm{SnO}_{2}$ film grown on $\mathrm{TiO}_{2}$ had better quality than those on sapphire because of smaller lattice mismatch. Using RSM of XRD and electron diffraction of TEM, the lattice constants of the $\mathrm{SnO}_{2}$ film were measured. The results of the lattice constants were almost the same as the bulk $\mathrm{SnO}_{2}$ from the interface of the film and substrate to the surface of the film. Although there were many defects at the interface in TEM image, the defects were decreased with the film thickness. By EBSD analysis, the Kernel average misorientation angles were measured for several vertical positions in the cross-section of the $\mathrm{SnO}_{2}$ film. Then, the misorientation angles were monotonically decreased from the interface to the surface. This result corresponded to the decrease of the defects in TEM image.

\section{ACKNOWLEDGEMENT}

The authors thank Prof. Ichikawa and Mr. Sato of Kumamoto University (KU) for their assistance with XRD, Dr. Yamamuro and Dr. Tsushida of KU for their assistance with EBSD and TEM, and Prof. Yoshimoto and Prof. Kida of KU for their help with AFM.

\section{REFERENCES}

[1] P. Karthick, D. Vijayanarayanan, M. Sridharan, A.K. Ananth, C. Sanjeeviraja, and K. Jeyadheepan, Thin Solid Films, 631, 1-11 (2017).

[2] S. Wu, Y. Li, J. Luo, J. Lin, Y. Fan, Z. Gan, and X. Liu, Opt. Express, 22, 4731 (2014).

[3] V. Fauzia, M.N. Yusnidar, L.H. Lalasari, A. Subhan, and A.A. Umar, J. Alloys Compd., 720, 79-85 (2017).

[4] K. Suematsu, W. Harano, T. Oyama, Y. Shin, K. Watanabe, and K. Shimanoe, Anal. Chem., 90, 11219-11223 (2018).

[5] N.S. Subramanian, B. Santhi, T. Sornakumar, G.K. Subbaraj, C. Vinoth, and G. Murugan, Ionics, 10, 273-282 (2004).

[6] C. Sankar, V. Ponnuswamy, M. Manickam, R. 
Mariappan, and R. Suresh, Appl. Surf. Sci., 349, 931-939 (2015).

[7] N. Barsan, J. Rebholz, and U. Weimar, Sensors Actuators, B Chem., 207, 455-459 (2015).

[8] G. T. Dang, T. Uchida, T. Kawaharamura, M. Furuta, A. R. Hyndman, R. Martinez, S. Fujita, R. J. Reeves, and M. W. Allen, Appl. Phys. Express, 9, 041101 (2016).

[9] T. Oshima, T. Okuno, and S. Fujita, Jpn. J. Appl. Phys., 48, 120207 (2009).

[10] O. Bierwagen, M.E. White, M.Y. Tsai, T. Nagata, and J.S. Speck, Appl. Phys. Express, 2, 106502 (2009).

[11] H. K. Summitt, and N. F. Borrelli, J. Appl. Phys., 37, 2200 (1966).

[12] K. D. Mc. Roberts, C. G. Fonstad, D. Hubert, Phys. Rev. B, 10, 5213 (1974)

[13] V. T. Agekyan, Phys. Status Solidi, 43, 11 (1977).

[14] K. J. Button, C. G. Fonstad, and W. Dreybrodt, Phys. Rev. B, 4, 4539 (1971).

[15] J. E. Dominguez, L. Fu, and X. Q. Pan, Appl. Phys. Lett., 81, 5168 (2002).

[16] M.Y. Tsai, M.E. White, and J.S. Speck, J. Cryst. Growth, 310, 4256-4261 (2008).

[17] T. Wang, A. Prakash, E. Warner, W.L. Gladfelter, and B. Jalan, J. Vac. Sci. Technol. A, 33, 020606 (2015).

[18] S. Hishita, P. Janeček, and H. Haneda, J. Cryst. Growth, 312, 3046-3049 (2010).

[19] M. E. White, M. Y. Tsai, F. Wu, and J. S. Speck, J. Vac. Sci. Technol. A, 26, 1300-1307 (2008).

[20] Y.H. Choi, and S.H. Hong, Sensors Actuators, B, 125, 504-509 (2007).

[21] Z. Zhu, J. Ma, L. Kong, C. Luan, and Q. Yu, J. Cryst. Growth, 324, 98-102 (2011).

[22] Z.G. Song, F. Ji, J. Ma, T. Ning, X.A. Pei, and Y.L. Tan, Adv. Mater. Res., 79-82, 759-762 (2009).

[23] G.P. Choi, Y.J. Park, W.S. Noh, and J.S. Park, Mater. Sci. Forum, 449-452, 997-1000 (2004).

[24] C. Luan, J. Ma, X. Yu, Z. Zhu, W. Mi, and Y. Lv, Vacuum, 86, 1333-1335 (2012).

[25] G.-H. Lee, Mater. Trans., 54, 2159-2161 (2013).

[26] D.H. Kim, J.H. Kwon, M. Kim, and S.H. Hong, J. Cryst. Growth, 322, 33-37 (2011).

[27] H.E. Cheng, D.C. Tian, and K.C. Huang, Procedia Eng., 36, 510-515 (2012).

[28] D.K. Lee, Z. Wan, J.S. Bae, H.B.R. Lee, J.H. Ahn, S.D. Kim, J. Kim, and S.H. Kwon, Mater. Lett., 166, 163-166 (2016).

[29] H. Wakabayashi, T. Suzuki, Y. Iwazaki, and M. Fujimoto, Jpn. J. Appl. Phys., 40, 6081-6087 (2001).

[30] S. T. Zhang, J. L. Rouviere, V. Consonni, H. Roussel, L. Rapenne, E. Pernot, D. Munoz-Rojas, A. Klein, and D. Bellet, Materials and Design, 132, 518-525 (2017).

[31] J. G. Lu, T. Kawaharamura, H. Nishinaka, Y. Kamada, T. Ohshima, and S. Fujita, J. Cryst. Growth, 299, 1-10 (2007).

[32] T. Kawaharamura, H. Nishinaka, and S. Fujita, Jpn. J. Appl. Phys., 47, 4669-4675 (2008).

[33] H. Tanoue, T. Taniguchi, S. Wada, S. Yamamoto, S. Nakamura, Y. Naka, H. Yoshikawa, M. Munekata, S. Nagaoka, and Y. Nakamura, Appl. Phys. Express, 8, $125502(2015)$

[34] K. Kaneko, H. Kawanowa, H. Ito, and S. Fujita, Jpn. J. Appl. Phys., 51, 020201 (2012).

[35] K. Okita, K. Inaba, Z. Yatabe, and Y. Nakamura, Jpn. J. Appl. Phys., 57, 065503 (2018).
[36] J.H. Kwon, Y.H. Choi, D.H. Kim, M. Yang, J. Jang, T.W. Kim, S.H. Hong, and M. Kim, Thin Solid Films, 517, 550-553 (2008).

[37] C. Luan, Z. Zhu, W. Mi, and J. Ma, Vacuum, 99, $110-114$ (2014).

[38] Z. Zhu, J. Ma, C. Luan, L. Kong, and Q. Yu, Appl. Surf. Sci., 257, 2516-2519 (2011).

[39] T. Okuno, T. Oshima, S.D. Lee, and S. Fujita, Phys. Status Solidi C, 8, 540-542 (2011).

[40] Z. Yatabe, T. Tsuda, J. Matsushita, T. Sato, T. Otabe, K. Sue, S. Nagaoka, and Y. Nakamura, Phys. Status Solidi C, 14, 1600148 (2017).

[41] T. Z. Win, K. Inaba, S. Kobayashi, T. Furukawa, Y. Kanetake, S. Miwa, T. Hashishin, and Y. Nakamura, Jpn. J. Appl. Phys., 59, 095503 (2020).

[42] J.W. Lee, J.H. Kim, S.K. Han, S.K. Hong, J.Y. Lee, S.I. Hong, and T. Yao, J. Cryst. Growth, 312, 238 (2010).

[43] T. Moriyama and S. Fujita, Jpn. J. Appl. Phys., 44, 7919 (2005).

[44] K. Koksal, B. Gonul, and M. Oduncuoglu, Eur. Phys. J. B, 69, 211-218 (2009).

[45] L. Saraf, Microscopy and Microanalysis, 17, 424-425 (2011).

(Received June 18, 2020; Accepted August 25, 2020; Published Online October 1, 2020) 